NASA TECHNICAL NOTE

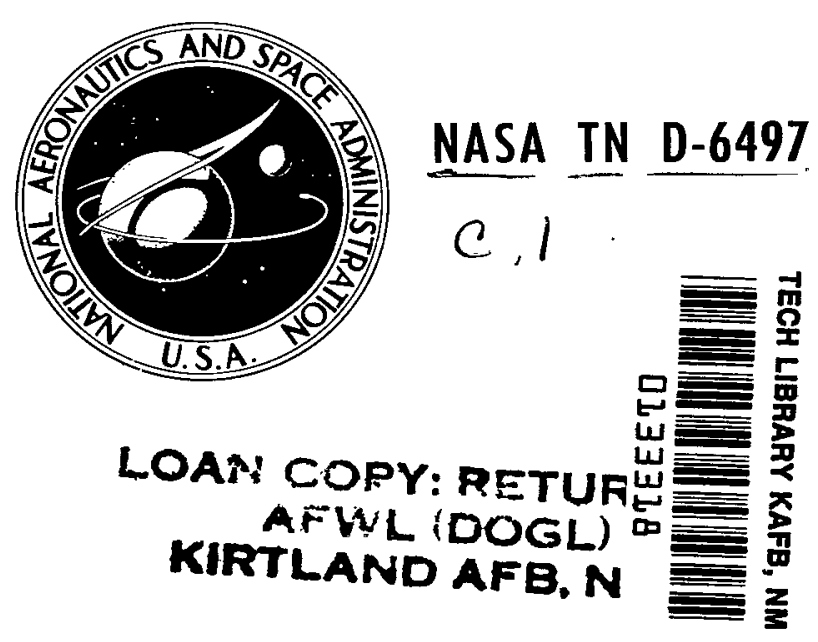

ELEMENTAL ANALYSIS OF A FRICTION
AND WEAR SURFACE DURING SLIDING USING AUGER SPECTROSCOPY

by Donald H. Buckley and Stephen V. Pepper

Lewis Research Center

Cleveland, Obio 44135

national aeronautics and Space administration - washington, D. C. - September 1971 


\begin{tabular}{|c|c|c|}
\hline $\begin{array}{l}\text { 1. Report No. } \\
\text { NASA TN D-6497 }\end{array}$ & 2. Government Accession No. & $\begin{array}{l}\||||||||||||||||||||||||||||| \mid \\
\square 1 \exists \exists \exists 18\end{array}$ \\
\hline \multirow{2}{*}{\multicolumn{2}{|c|}{$\begin{array}{l}\text { 4. Title and Subtitle ELEMENTAL ANALYSIS OF A FRICTION AND } \\
\text { WEAR SURFACE DURING SLIDING USING AUGER SPECTRO- } \\
\text { SCOPY }\end{array}$}} & $\begin{array}{l}\text { 5. Report Date } \\
\text { September } 1971\end{array}$ \\
\hline & & 6. Performing Organization Code \\
\hline \multicolumn{2}{|c|}{$\begin{array}{l}\text { 7. Author(s) } \\
\text { Donald H. Buckley and Stephen V. Pepper }\end{array}$} & $\begin{array}{l}\text { 8. Performing Organization Report No. } \\
\text { E-6428 }\end{array}$ \\
\hline \multirow{3}{*}{\multicolumn{2}{|c|}{$\begin{array}{l}\text { 9. Performing Organization Name and Address } \\
\text { Lewis Research Center } \\
\text { National Aeronautics and Space Administration } \\
\text { Cleveland, Ohio } 44135\end{array}$}} & $\begin{array}{l}\text { 10. Work Unit No. } \\
129-03\end{array}$ \\
\hline & & 11. Contract or Grant No. \\
\hline & & 13. Type of Report and Period Covered \\
\hline \multirow{2}{*}{\multicolumn{2}{|c|}{$\begin{array}{l}\text { 12. Sponsoring Agency Name and Address } \\
\text { National Aeronautics and Space Administration } \\
\text { Washington, D. C. } 20546\end{array}$}} & Technical Note \\
\hline & & 14. Sponsoring Agency Code \\
\hline
\end{tabular}

16. Abstract

A friction and wear apparatus incorporating an Auger cylindrical mirror spectrometer has been constructed. The spectrometer in the apparatus provides the capability of analyzing for all elements heavier than helium present on the sliding friction and wear surface of interest in $0.10 \mathrm{sec}$. Adhesion and transfer of silver, aluminum, and copper to a steel surface were monitored while transfer was occurring. Variations in transfer mode could be detected. Adsorption of gases containing oxygen to a copper transfer film and subsequent friction-initiated desorption of that film were monitored with the Auger Spectrometer. The Auger cylindrical mirror spectrometer affords the friction, wear, and lubrication researcher a tool and capabilities heretofore unavailable.

17. Key Words (Suggested by Author(s))

Auger spectroscopy

18. Distribution Statement

Friction

Unclassified - unlimited

Wear

Elemental analysis

19. Security Classif. (of this report)

Unclassified

20. Security Classif. (of this page)

Unclassified
21. No. of Pages

19
22. Piice*

$\$ 3.00$

*For sale by the National Technica! Information Service, Springfieid, Virginia 22151 


\title{
ELEMENTAL ANALYSIS OF A FRICTION AND WEAR SURFACE DURING \\ SLIDING USING AUGER SPECTROSCOPY
}

\author{
by Donald H. Buckley and Stephen V. Pepper \\ Lewis Research Center
}

\begin{abstract}
SUMMARY
An Auger cylindrical mirror spectrometer has been incorporated into a friction and wear apparatus. The spectrometer can analyze for all elements heavier than helium present on a friction and wear surface. The instrument response is sufficiently fast to allow a chemical analysis of the surface in 0.10 second. The surface can be continuously analyzed while the experiment is in progress, and better insight into those chemical factors influencing friction and wear can thereby be provided.

In sliding friction experiments, transfer of silver, aluminum, and copper to a steel surface was observed. Transfer took place without any attempt to sputter clean the steel surface. This occurred in the first pass of the rider across the steel disk. Variations in the mode of metal transfer could also be detected. Gases containing oxygen were adsorbed to a copper transfer film, and its subsequent friction-initiated desorption was monitored. Auger spectrometry provides the lubrication researcher with a method of examining the lubrication process dynamically.
\end{abstract}

\section{INTRODUCTION}

Adhesion, friction, and wear of contacting solids is markedly dependent upon the nature of surface films. Adsorbed and reacted films (refs. 1 to 3 ) exert an influence on these properties. In addition, equilibrium segregation of elements in the bulk of metals to the surface can alter adhesion and friction behavior (ref. 4).

When two surfaces are in sliding or rubbing contact, the energy put into the interface can alter the nature of surface reactions. For example, chemical reactions may be initiated in the contact zone that will not occur outside that zone. It is, therefore, very important in the interpretation of the adhesion, friction, and wear properties of materials to be able to follow changes in surface chemistry while they occur, namely, 
during the sliding or rubbing process. In the past this has not been possible, and surface chemical activity during the dynamic experiment has been inferred from postexperimental analysis.

Auger emission spectrometry is particularly useful in friction, wear, and lubrication studies because it can very readily detect the light elements carbon, sulfur, nitrogen, phosphorous, and oxygen. It is sufficiently sensitive to enable the detection of an element such as oxygen to surface coverages of as little as 0.01 of a monolayer (ref. 5).

The objective of this investigation was to use Auger emission spectrometry in a friction and wear apparatus to provide the capability of continuously monitoring the surface elements. Elemental analysis could be made of the surface when stationary or while moving. The transfer, with sliding, of aluminum, silver, and copper to a steel surface was studied. Adsorption of an oxygen-containing gas to a wear transfer film was also investigated. Sliding friction experiments were conducted with a hemispherical rider sliding on a rotating flat disk at loads of 500 grams and at speeds of 20 centimeters per minute. All experiments were conducted at $23^{\circ} \mathrm{C}$.

\section{EXPERIMENTAL APPARATUS AND PROCEDURE}

\section{Specimens}

The friction and wear specimens consisted of a disk specimen 6.5 centimeters in diameter and 1.2 centimeters in thickness and a hemispherical rider with a 0.5 -centimeter radius. The specimens are shown in the apparatus schematic in figure 1. The disk specimen is mounted on a drive shaft which is rotated with a magnetic drive assembly. The drive assembly provides for rotation at various speeds (in this study, $20 \mathrm{~cm} / \mathrm{min}$ ). The rider specimen is mounted in an insulated holder to one end of a stainless-steel shaft. Friction and wear experiments are conducted with the rider specimen loaded against the disk surface. As the disk is rotated, the rider scribes a circular wear track on the flat surface of the disk. The load used in this investigation was 500 grams, and the temperature was $23^{\circ} \mathrm{C}$.

\section{Experimental Chamber}

The experiments are conducted in a vacuum chamber (see fig. 1). The vacuum system is pumped by sorption pumps and an ion pump. Pressure in the vacuum system is read with a nude ionization gage. The vacuum system achieved a pressure of $1 \times 10^{-10}$ torr after bakeout at $250^{\circ} \mathrm{C}$. 


\section{Measurements}

The friction force between the disk and rider specimen is continuously recorded during the experiment. The beam which contains the rider specimen is welded into a bellows assembly which is gimbal mounted to the vacuum system. The gimbal mounting permits dead-weight loading of the rider against the disk surface (fig. 1). At right angles to the dead-weight loading, the beam containing the rider can move in two directions in the horizontal plane. Movement of the rider (with the disk as it rotates) is restrained by a cable which is attached to a beryllium-copper ring. The ring contains four sets of strain gages. These gages measure the frictional force between the disk and rider specimen. The friction force is recorded on a strip chart.

\section{Specimen Preparation and Cleaning}

The disk specimens are finish ground on metallurgical papers to a grit of 600 . They are then diamond polished with 6-micrometer and finally 3-micrometer diamond paste. The disks are rinsed with acetone and then with absolute ethyl alcohol.

The specimens are cleaned by ion bombardment in the experimental chamber. The disk specimen is insulated from ground on the drive shaft. Two copper rods are brought to the disk from feed-throughs insulated from ground. The end of one rod terminates 0.5 centimeter from the circumferential edge of the disk specimen. This terminal establishes the positive potential in the glow discharge. The second rod has a beryllium-copper leaf attached to it. The end of the leaf opposite its attachment to the rod makes a "wiping" type of contact with the circumferential edge of the disk. The entire flat of the disk is cleaned by the sputtering as a result of being immersed in the glow discharge. The specimens are ion-bombarded by bleeding research-grade argon gas into the system until a pressure of about 0.02 torr is achieved. A direct-current power supply is used to supply 400 to 500 volts between the disk and the floating electrode. With the negative potential on the disk positively charged, argon ions bombard and sputter clean the specimen surfaces. Variations in the argon pressure can alter the voltage necessary for efficient sputtering. The higher the pressure, the lower the voltage needed.

\section{Auger Analysis}

Elemental analysis of the disk specimen surface can be made before, during, and after the friction and wear experiment by using an Auger cylindrical mirror analyzer 
with an integral electron gun. The point of rider to disk contact passes under the Auger beam 20 seconds after the disk moves out of the contact zone. This time element can be produced by increasing the speed at which the disk rotates. The disk could rotate over a broad range of speed, and Auger analysis could still be performed. The Auger analyzer is a commercial unit, the essential elements of which are described in reference 6.

The primary beam of electrons is directed at the disk surface by a beam from the electron gun in the Auger cylindrical mirror analyzer (fig. 2). The beam is focused on the wear track scribed by the rider in sliding contact with the disk. The beam contact is $180^{\circ}$ away from the rider on the disk surface. The beam spot diameter is $0.2 \mathrm{milli}-$ meter. The gun contains deflection plates which allow positioning of the beam on the disk surface.

The secondary electrons come off the specimen surface, pass through the outer cylindrical can opening (see fig. 2), and then pass through slits in an inner cylinder which serves as an energy analyzer. They are collected by the electron multiplier. Elemental identification is accomplished by analysis of the detected secondary-electron energies. The Auger electrons that appear in the secondary-electron distribution "fingerprint" the surface elements to a depth of approximately four atomic layers (ref. 7). Some Auger electron energies for elements seen in this preliminary investigation are presented in table $I$. The reader who is interested in the details of Auger analysis is referred to references 8 and 9 .

Auger traces are displayed on an oscilloscope. The sweep control module permits a full spectrum scan for those elements of interest in friction, wear, and lubrication in 0.10 second. Thus, there exists the capability of monitoring a moving or rotating surface and detecting dynamic variations in surface chemistry.

\section{RESULTS AND DISCUSSION}

\section{Steel Surface}

An Auger analysis of a standard 1045 steel disk surface was conducted. The disk surface was solvent cleaned prior to insertion into the vacuum chamber. No attempt was made to remove surface oxides. The resulting Auger trace is presented in figure 3(a). Peaks for carbon, oxygen, and iron were readily detected from the surface. The carbon peak can originate from two sources: (1) carbon from the steel which is present on the surface, and (2) the adsorption of carbon monoxide to the surface from the vacuum system. The former source of carbon is a large contributor to its presence on iron surfaces. Iron with only parts per million (14 ppm) of carbon in the bulk has a 
surface rich in carbon. The carbon segregates to the surface when the iron is heated (refs. 8 to 10 ).

In figure 3(b) another Auger trace was taken at higher sensitivity with the range of electron energies scan limited to oxygen and iron. The Auger peaks of oxygen and iron are readily discernible.

\section{Silver Sliding on Steel}

A silver rider sliding on a steel disk showed that transfer of silver to the steel surface occurred. Transfer was followed with each pass by using the Auger spectrometer. A complete elemental spectrum trace taken during the 50th pass of the silver rider over the steel disk is presented in figure 4. The elements readily detected are iron, carbon, oxygen, and silver. A 60-electron-volt iron peak is present in figure 4. This peak did not appear in figure 3 because the portion of the energy spectrum revealing this peak was not scanned in figure 3. The silver results from transfer of silver to the steel disk. The transferred silver is either less than four atomic layers deep, or more likely as will be shown later, is not uniform. That is, there are locations on the disk surface where silver may be transferred and other areas where adhesion and transfer have not taken place. Both of these possibilities are consistent with the observation that iron, carbon, and oxygen can still be detected together with the silver.

The intensity of a silver peak was monitored with each pass of the silver rider over the disk surface. The silver peak intensity was measured relative to the intensity of an iron peak. The silver peak initially grew with successive passes, while the iron peak diminished in intensity. The pattern was taken at the same disk location on each pass (by the use of a triggering device) to ensure that variations in transfer with location did not alter results. The results obtained are presented in figure 5.

With each of the first 12 passes of the rider over the disk surface, the silver peak continued to increase in intensity while the iron peak continued to decrease, which indicated successive buildup of silver. In the 16 th pass, the relative peak intensity dropped drastically indicating back-transfer of the silver from the disk to the rider. Thus, adhesion of the silver to the steel through the oxide film initially occurs, and silver adhesion then accounts for a buildup of silver. When the film becomes sufficiently thick, shearing of silver cohesive bonds can occur within the transferred film.

When sliding was continued, silver began again to build up on the surface, as evidenced by the increase in the relative peak intensities at the 15th pass (see fig. 5).

The adhesion of silver to steel and its transfer to that surface is very interesting. It has been frequently held that adhesion should not occur where metals are insoluble in the solid state (ref. 11). Silver and iron are mutually insoluble, and yet adhesion and 
transfer to the steel surface are seen with Auger analysis. This occurs even with the first pass. It cannot be argued that binding of silver is occurring to either carbon or oxygen since silver forms no stable compounds with carbon and silver-oxygen compounds are not stable under the conditions of these experiments. Further, simple adhesion experiments of silver to iron indicate that silver will adhere and transfer to iron (ref. 8).

\section{Aluminum Sliding on Steel}

Adhesion experiments have indicated that aluminum will transfer readily to iron (ref. 9). It might therefore ke anticipated that, during sliding, aluminum would also transfer. A sliding friction experiment was conducted with aluminum sliding on steel. A very strong iron Auger peak appears at 60 electron volts. An aluminum peak occurs at about 70 electron volts.

Auger traces taken before and during the sliding friction experiment are presented in figure 6 .

In figure 6(a) the Auger trace shows the iron 60-electron-volt peak and the carbon peak at 270 electron volts. With a single pass of the aluminum rider over the disk (fig. 6(b)), a small bulge appears in the right portion of the iron 60-electron-volt peak. This is the appearance of an aluminum peak. Aluminum has transferred to the steel surface during the first pass of the rider over the disk. Note that the carbon peak has undergone a reduction in size.

After two passes of the aluminum rider over the disk surface, the trace of figure 6(c) was obtained. The aluminum peak has undergone further development toward forming a distinct peak indicating the transfer of additional aluminum to the iron surface. The carbon peak has undergone a further decrease in size. The decrease in the size of the carbon peak is to be anticipated as the carbon present on the iron surface is covered by aluminum.

With 20 passes of the aluminum rider over the disk surface, a peak separate and fully distinct from the iron peak has formed (fig. 6(d)). Again, the carbon peak has decreased in intensity. Note that since the aluminum peak is not fully resolved from the iron peak, the amount of aluminum transferred to the steel surface between 2 and 20 passes is much greater than would appear simply from relative peak height differences for the aluminum.

The transfer of aluminum to the steel surface was followed with each pass of the rider over the surface. The relative aluminum to carbon peak intensity is plotted in figure 7. From pass 1 to 12, the amount of aluminum transferred to the steel surface continues to increase gradually. This might be referred to as mild adhesive transfer. In the 12 th to the 16 th pass, the amount of metal transfer increases markedly. Thus, there is a transition from mild to severe adhesion occurring. 
In the process of adhesive wear, mild wear is associated with the transfer of a thin film relatively uniform in thickness. The fracture of cohesive aluminum bonds takes place near the interface in the surficial layers. Frequently, however, transfer of large particles of metal from one surface to another occurs. This takes place in the severe wear process with cohesive fracture occurring away from the interface in the cohesively weaker of the two materials (in the present case, aluminum).

\section{Copper Sliding on Steel}

A single pass of copper rider was made on a steel disk. Auger traces were taken at three locations separated by approximately $120^{\circ}$. The three locations were arbitrarily selected to determine if transfer of metal was uniform around the disk. The three traces were all taken on the same frame of film. The traces are presented in figure 8. The copper peak at 120 electron volts and the carbon peak at 270 electron volts are presented. There are slight variations in peak heights for the copper peaks indicating variations in the amount of copper transferred to the disk at various locations in the circumferential track. It is, therefore, apparent from figure 8 that, if the adhesive wear process is to be quantitatively characterized with Auger analysis, the same location on the surface must be continuously monitored.

A very important aspect of lubrication systems is the ability of the lubricant to react with the surface and form protective films which reduce adhesion, friction, and adhesive wear. Until now there has been no good reliable way to follow lubricant interaction with the surface while it takes place. Auger spectrometry now provides that capability. Thus, general interactions with the surface as well as surface reactions, initiated by friction, can be followed.

The "lubricant" oxygen, which is nearly always present, is probably one of the most effective lubricants in reducing metallic adhesion.

In order to establish that Auger could be used to follow the results of surface reactions initiated by the friction process, 20 passes of a copper rider were made over a steel disk. The adsorption of residual gases containing oxygen (water, carbon monoxide) on the freshly transferred copper was monitored. The oxygen peak is shown in figure 9(a) just 0.5 minute after sliding had ceased. A well defined oxygen peak is readily discernible. These gases continue to chemisorb to the surface for approximately 5 minutes, as shown by the data of figure 10 .

An examination of figure 10 indicates a drastic change in the uptake of oxygen to the copper from 4 to 5 minutes after sliding had ceased. This type of adsorption is not the normally observed behavior for metal-gas interactions. Usually adsorption is greatest initially, and as the surface becomes covered, uptake decreases. The heat of 
adsorption also decreases with increased surface coverage (ref. 12). With a sliding friction experiment the energy put into shearing of copper cohesive bonds at the interface may heat the surface sufficiently to impede adsorption. When the surface is sufficiently cool (after $4 \mathrm{~min}$ ) adsorption takes place readily. It is of interest to note that the surface has become saturated at 5 minutes.

Generally a clean strain-free copper surface will not readily adsorb oxygen at the ambient pressures at which these experiments were conducted. The copper transferred to the steel disk surface in these experiments is highly strained. Straining of metals can markedly increase their chemical reactivity. It may also influence the sticking coefficient of gases to the clean transferred metal film.

Figure $9(\mathrm{~b})$ shows the size of the oxygen peak after 10 minutes. In figure 9 (a) iron peaks are discernable through the oxygen and transferred copper. With the increased surface coverage in figure $9(b)$ the iron peaks are not readily detected. The copper peaks when scanned were, however, still detected. These results indicate the ability of Auger to follow the active nature of wear material.

The ability of the sliding friction process to desorb chemisorbed oxygen from a surface is indicated in figure $9(\mathrm{c})$. This figure shows the drastic reduction in the oxygen peak of figure $9(\mathrm{~b})$ when sliding across the surface is resumed. Note also the reappearance of the iron peaks. These changes reflect desorption of the oxygen from the transferred copper. The frictional energy associated with sliding is sufficient to dissociate the oxygen to copper bond.

\section{SUMMARY OF RESULTS}

Preliminary sliding friction and wear experiments using an Auger cylindrical mir ror spectrometer have produced the following results:

1. The changes in surface elemental composition that takes place during a dynamic friction and wear experiment can be followed with an Auger cylindrical mirror spectrometer. This can be accomplished while events are occurring and can thereby provide the capability of following metal transfer, lubricant-surface interaction, and frictioninitiated surface changes.

2. Transfer and changes in the mode of transfer were followed for silver, aluminum, or copper sliding on a steel surface. All three metals were found to transfer to a steel surface during a sliding friction experiment. These results are in agreement with earlier adhesion experiments which indicate transfer of these metals to an iron surface.

3. The result of interaction of various gases with the friction and wear surface can also be monitored. In this investigation, the uptake of oxygen-containing gases to a freshly transferred wear film of copper on steel was followed. 
4. Auger cylindrical mirror analysis can be effectively accomplished on rotating surfaces.

Lewis Research Center,

National Aeronautics and Space Administration, Cleveland, Ohio, July 13, 1971, 129-03.

\section{REFERENCES}

1. Bowden, Frank P.; and Tabor, David: The Friction and Lubrication of Solids. Part II. Clarendon Press, 1964.

2. Bowden, F. P.; and Rowe, G. W.: The Adhesion of Clean Metals. Proc. Roy Soc. (London), Ser. A, vol. 233, no. 1195, Jan. 10, 1956, pp. 429-442.

3. Buckley, Donald H. : Influence of Chemisorbed Films of Various Gases on Adhesion and Friction of Tungsten. J. Appl. Phys., vol. 39, no. 9, Aug. 1968, pp. 42244233.

4. Ferrante, John; and Buckley, Donald H. : Auger Electron Spectroscopy Study of Surface Segregation in Copper-Aluminum Alloys. NASA TN D-6095, 1970.

5. Musket, Ronald G. ; and Ferrante, John: Auger Electron Spectroscopy Study of Oxygen Adsorption on W(110). J. Vac. Sci. Tech., vol. 7, no. 1, 1970, pp. 1417.

6. Palmberg, P. W.; Bohn, G. K. ; and Tracy, J. C.: High Sensitivity Auger Electron Spectrometer. Appl. Phys. Letters, vol. 15, no. 8, Oct. 15, 1969, pp. 254-255.

7. Palmberg, P. W. : and Rhodin, T. N. : Auger Electron Spectroscopy of fcc Metal Surfaces. J. Appl. Phys., vol. 39, no. 5, Apr. 1968, pp. 2425-2432.

8. Taylor, Norman J.; Auger Electron Spectrometer as a Tool for Surface Analysis (Contamination Monitor). Vac. Sci. Tech., vol. 6, no. 1, Jan./Feb. 1969, pp. 241-245.

9. Dooley, George J., III. ; and Haas, T. W. : Auger Electron Spectroscopy: Metallurgical Applications. J. Metals, vol. 22, no. 11, Nov. 1970, pp. 17-24. 10. Buckley, Donald H.: Adhesion of Various Metals to a Clean Iron (011) Surface Studied with LEED and Auger Emission Spectroscopy. NASA TN D-7018, 1971. 
11. Roach, A. E. ; Goodzeit, C. L. ; and Hunnicutt, R. P.: Scoring Characteristics of Thirty-Eight Different Elemental Metals in High-Speed Sliding Contact with Steel. Trans. ASME, vol. 78, no. 8, Nov. 1956, pp. 1659-1667.

12. Hayward, D. O. ; and Trapnell, B. M. W.: Chemisorption. Second ed., Butterworth Publ., 1964.

13. Chang, Chuan C.: Auger Electron Spectroscopy. Surface Sci., vol. 25, no. 1, Mar. 1971, pp. 53-79.

TABLE I. - SELECTED AUGER

ELECTRON ENERGIES OF

VARIOUS ELEMENTS

\begin{tabular}{l|c|}
\hline Element & $\begin{array}{c}\text { Auger electron } \\
\text { energies, } \\
\mathrm{eV} \\
(\mathrm{a})\end{array}$ \\
\hline Carbon & 270 \\
Oxygen & 530 \\
Iron & $60,600,650,710$ \\
Sulfur & 150 \\
Aluminum & 70,118 \\
Copper & $57,60,120$ \\
Silver & $72,268,308,360$ \\
\hline
\end{tabular}




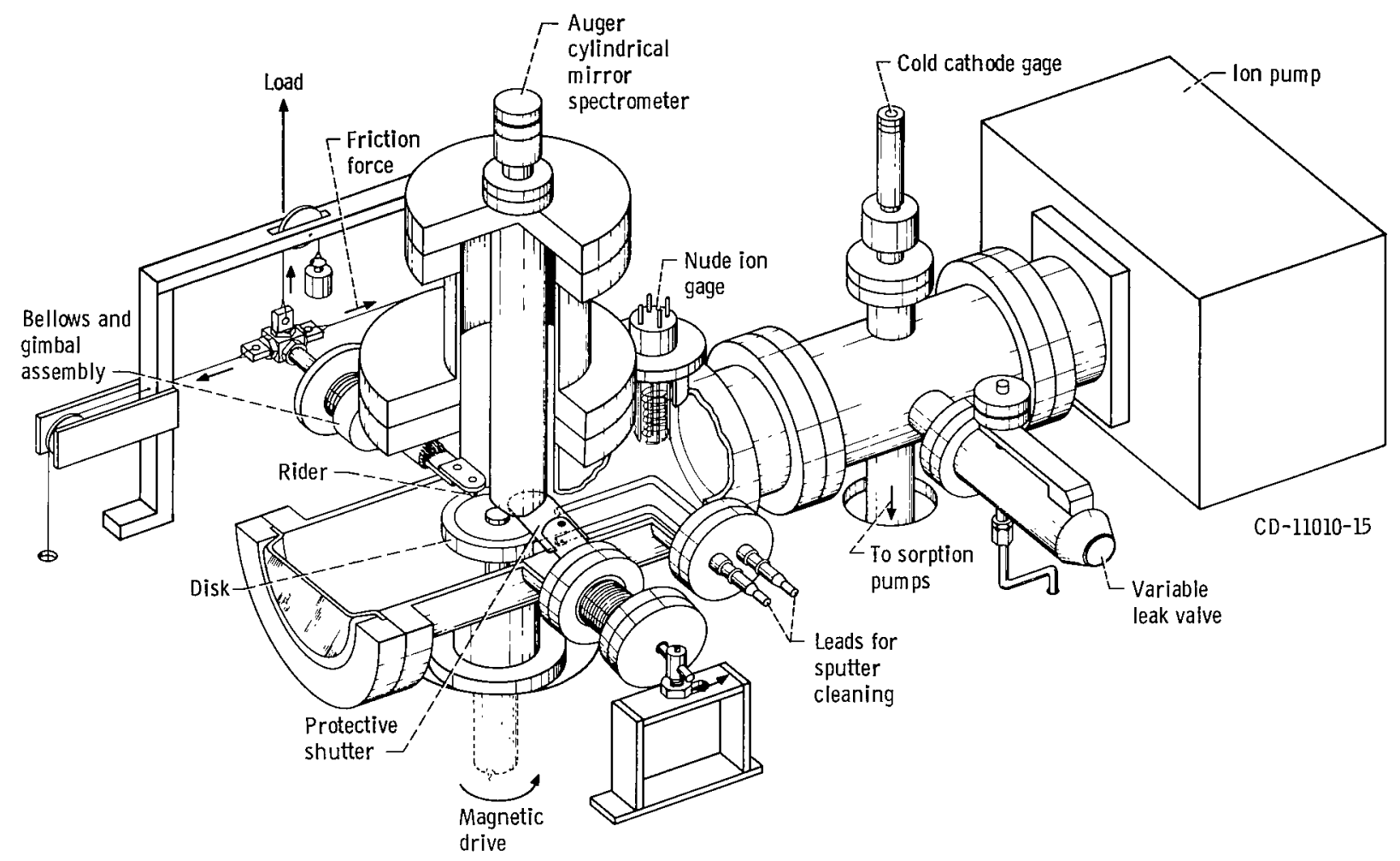

Figure 1. - Friction apparatus with Auger spectrometer. 


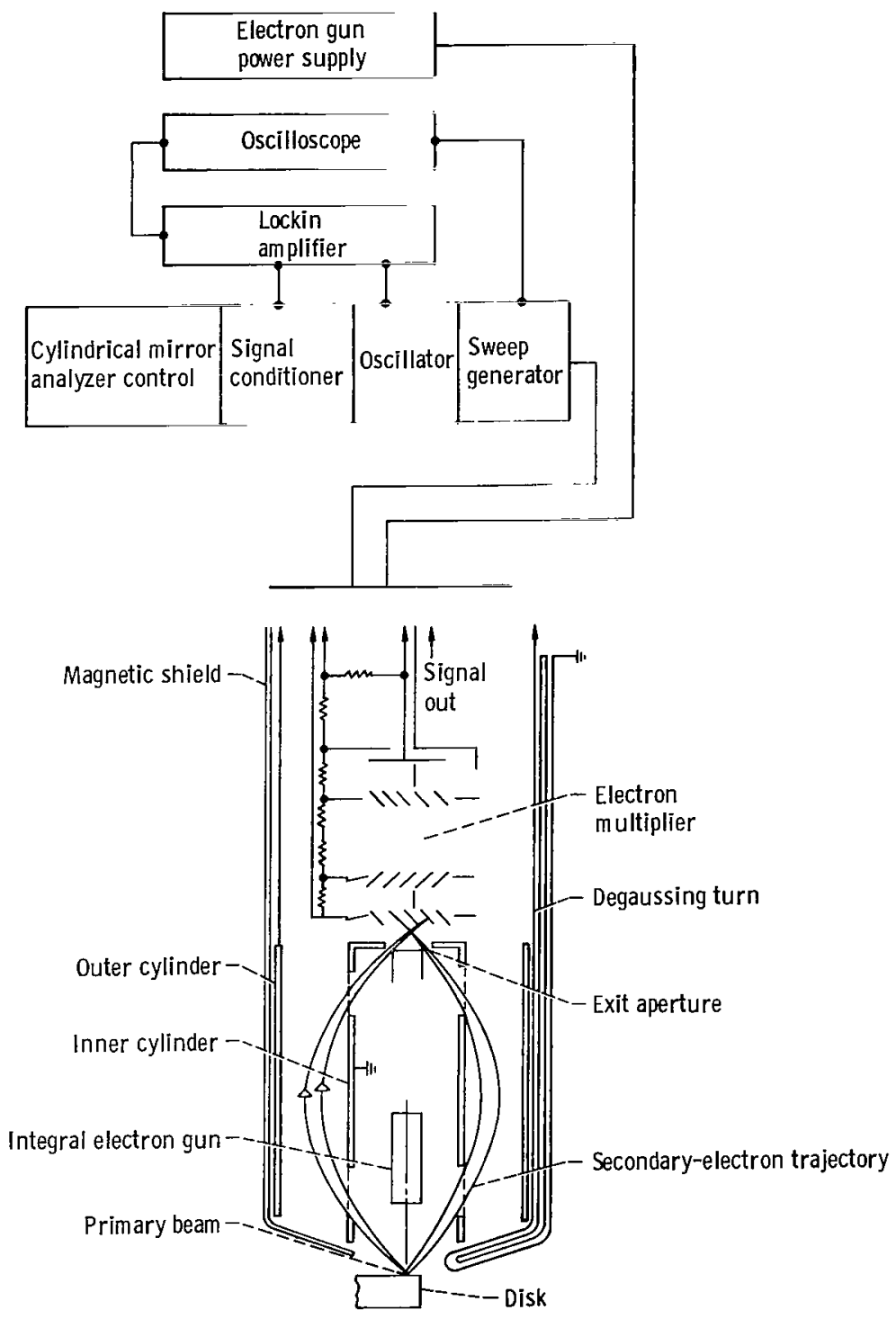

Figure 2. - Schematic of Auger cylindrical mirror analyzer. 


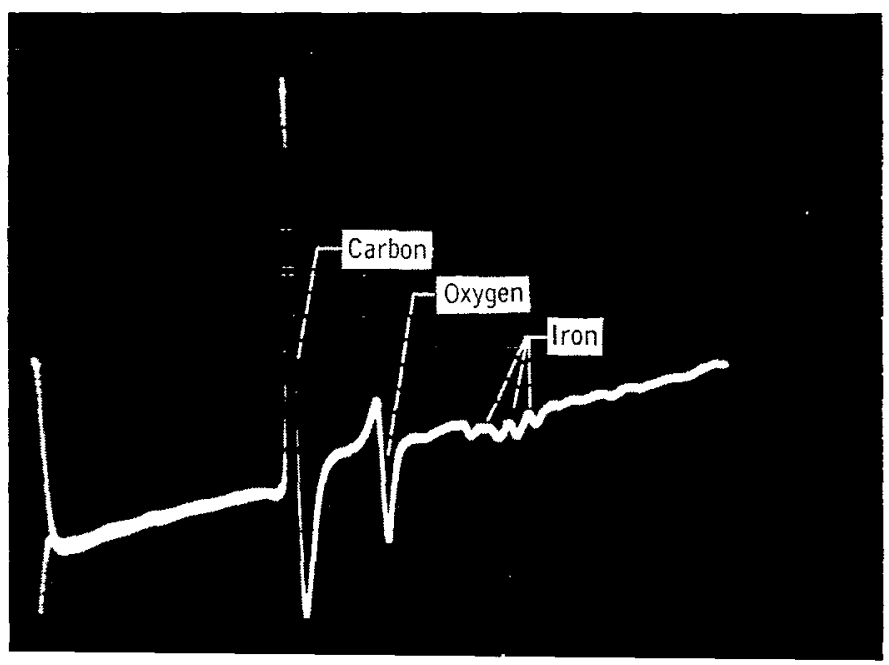

(a) Spectrum showing all elements detected.

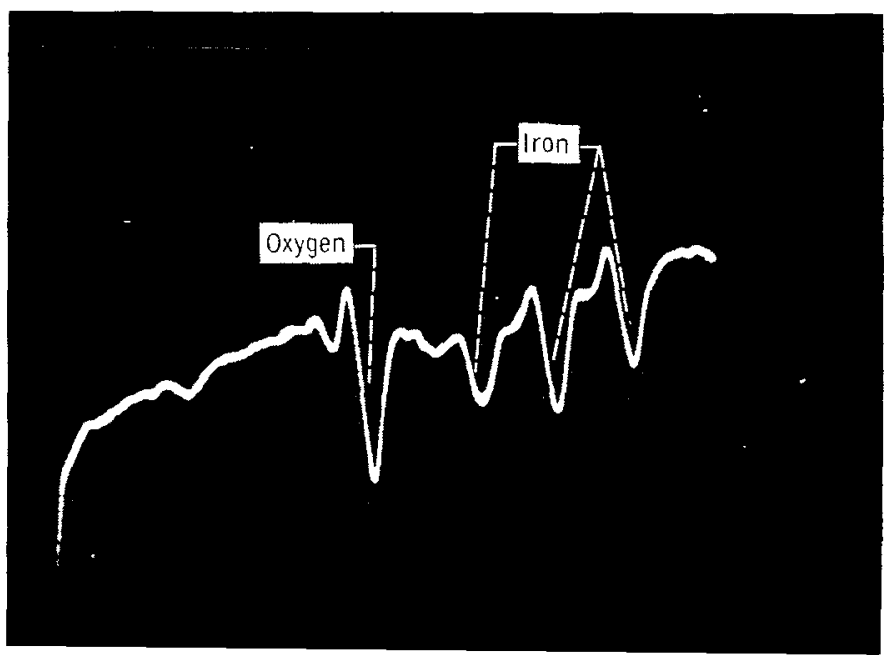

(b) Portion of spectrum with increase in sensitivity to show iron peaks.

Figure 3. - Auger analysis of rotating 1045 steel disk surface. Sliding velocity, 20 centimeters per minute; load, 500 grams; temperature, $23^{\circ} \mathrm{C}$. 


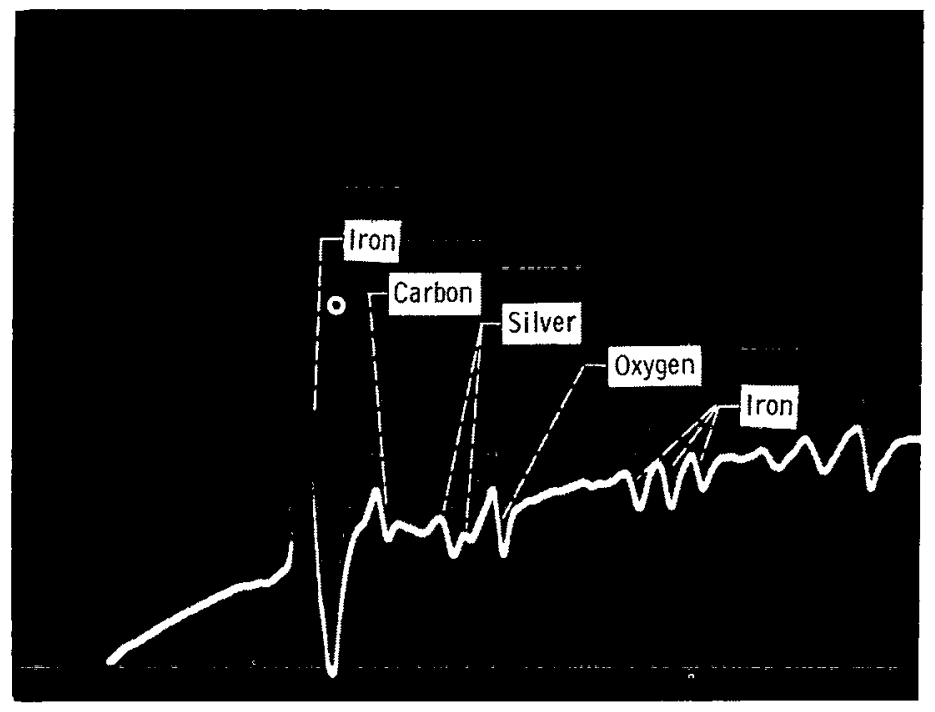

Figure 4. - Auger analysis of steel disk during 50th pass of silver rider over steel disk surface. Sliding velocity, 20 centimeters per minute; load, 500 grams; temperature, $23^{\circ} \mathrm{C}$.

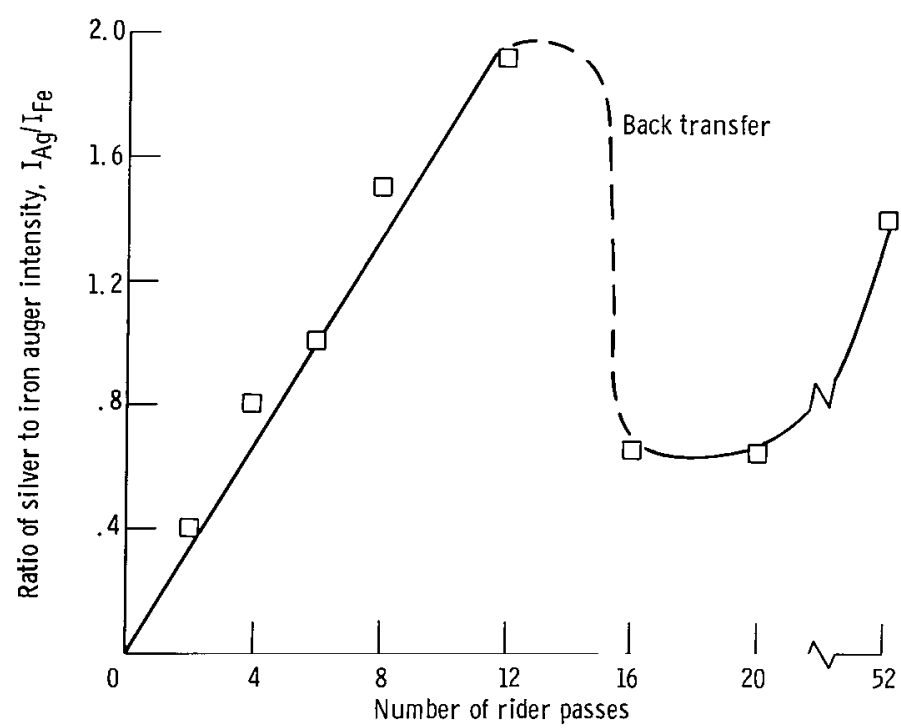

Figure 5. - Detection of silver transferred to steel surface during sliding friction experiment. Sliding velocity, 20 centimeters per minute; 500 grams; load, temperature, $23^{\circ} \mathrm{C}$. 


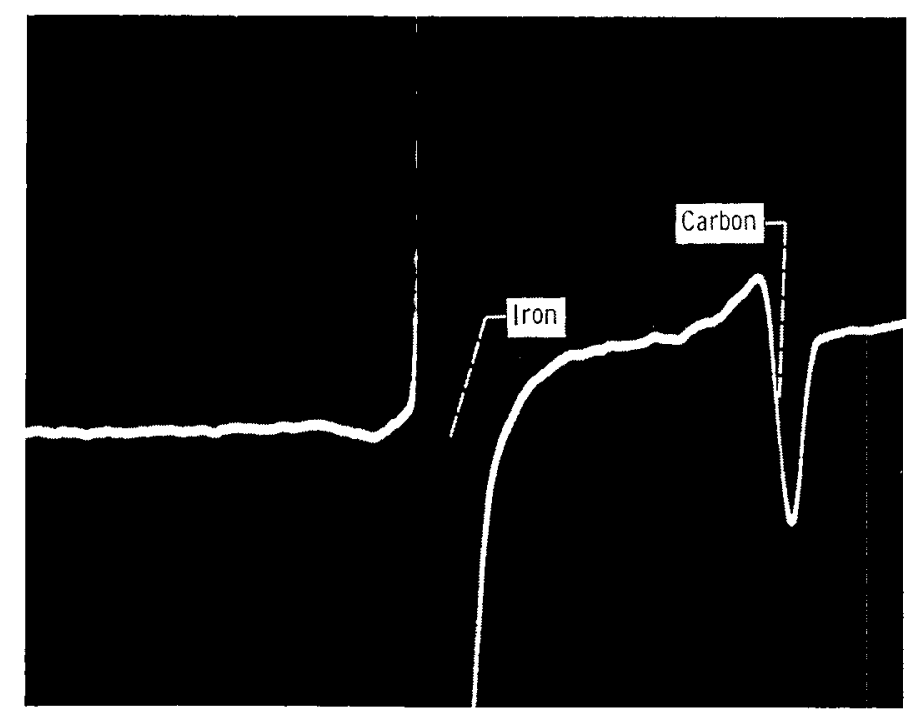

(a) Before contact.

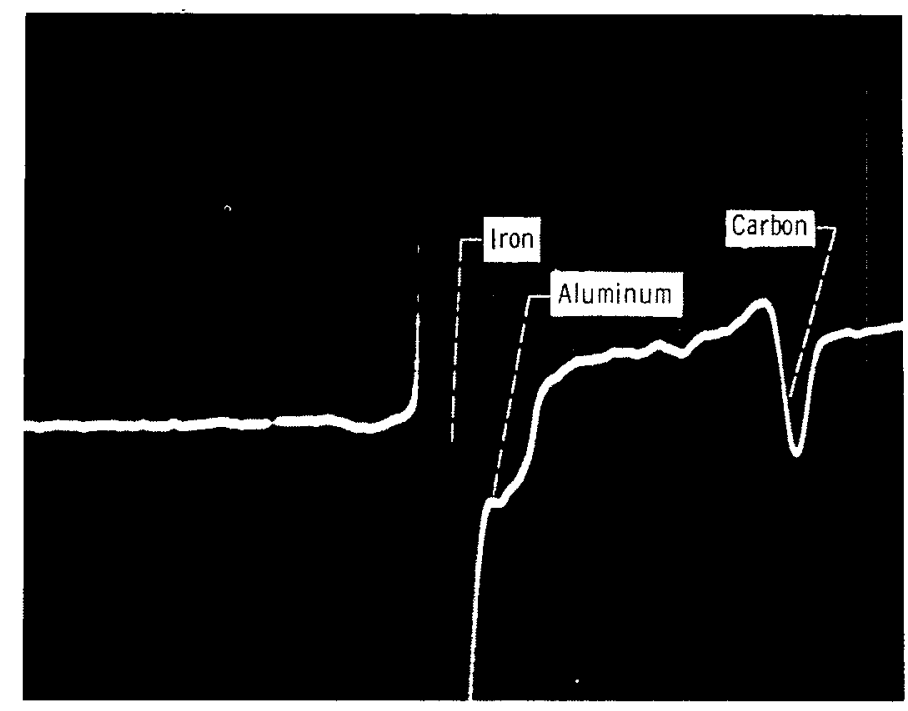

(c) After passes.

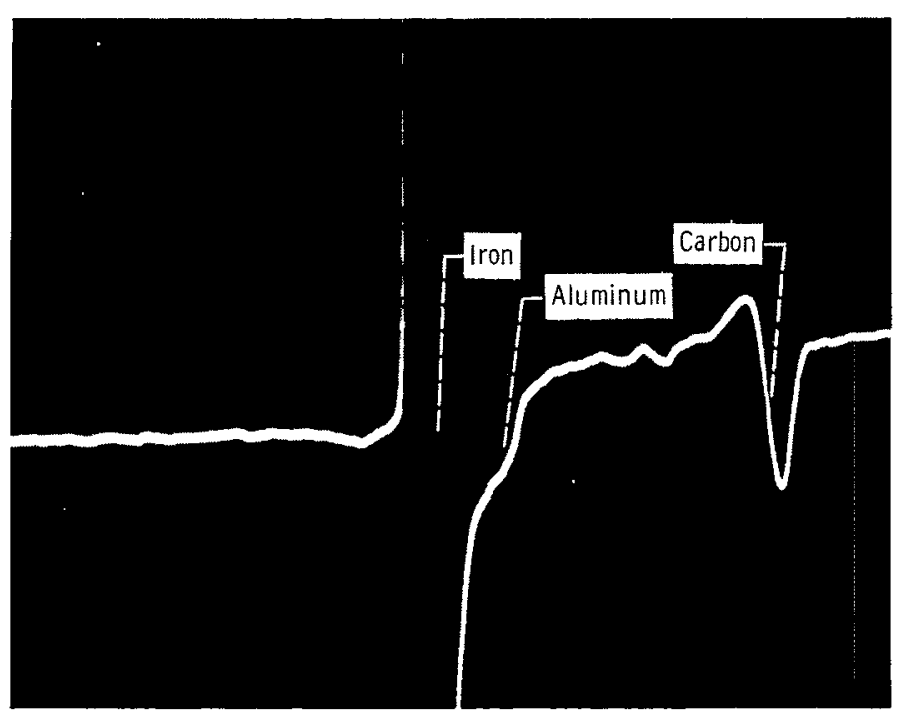

(b) After pass.

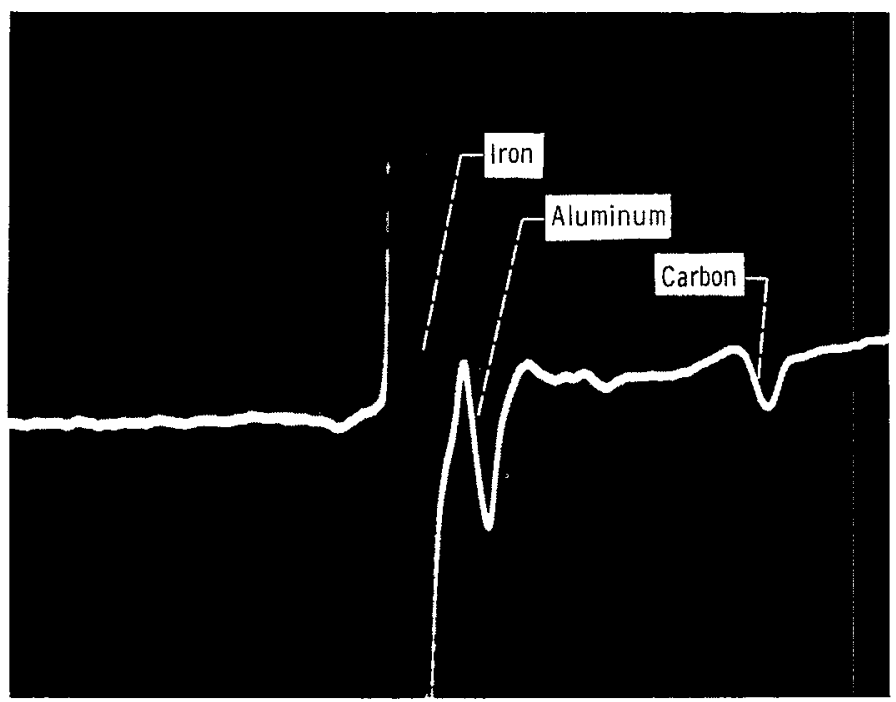

(d) After 20 passes.

Figure 6. - Auger analysis of steel disk surface before and during sliding contact with aluminum rider. Sliding velocity, 20 centimeters per minute; load, 500 grams; temperature, $23^{\circ} \mathrm{C}$ 


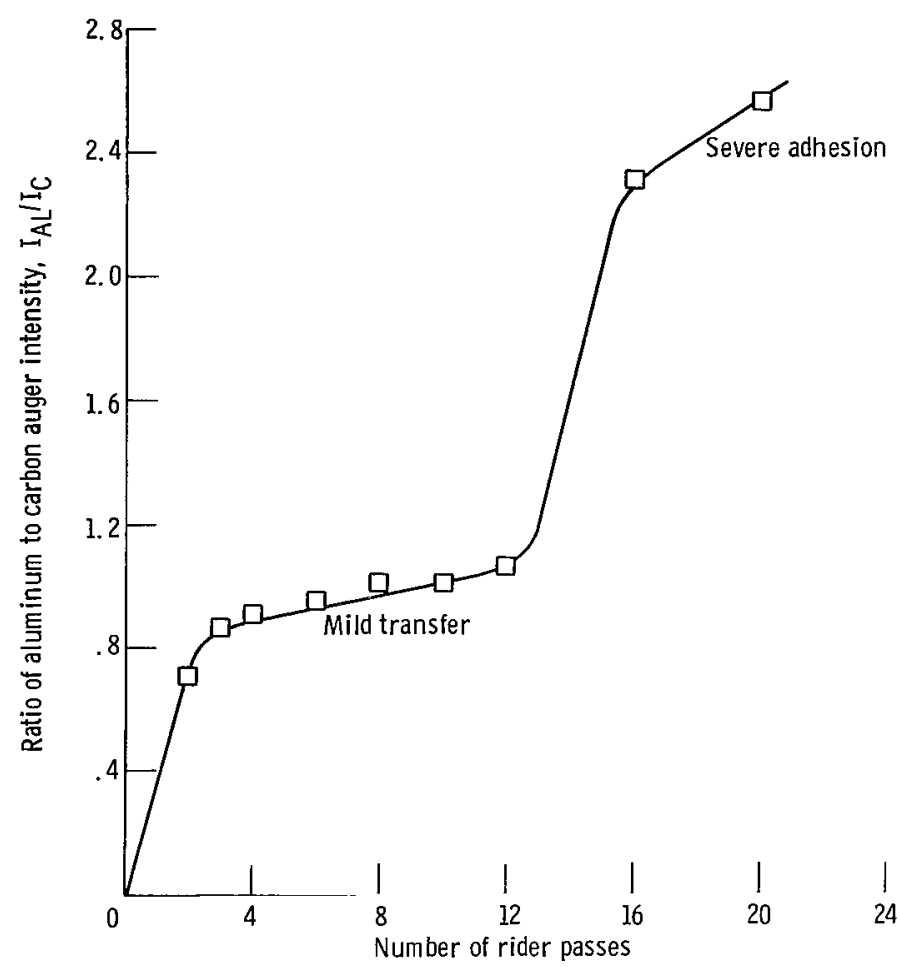

Figure 7. - Detection of alum inum adhesive transfer to steel surface during sliding friction experiment. Sliding velocity, 20 centimeters per minute; 500 grams; load, temperature, $23^{\circ} \mathrm{C}$.

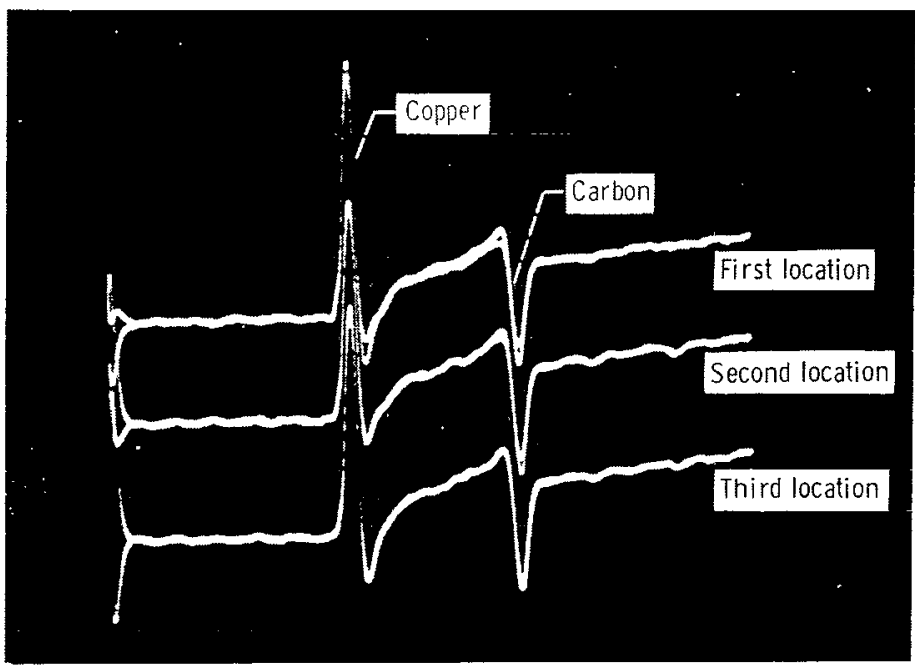

Figure 8. - Variation in copper and carbon peak weight in circumferential wear track of steel disk during single pass of copper rider over disk surface. Sliding velocity, 20 centimeters per minute; load, 500 grams; temperature, $23^{\circ} \mathrm{C}$. 


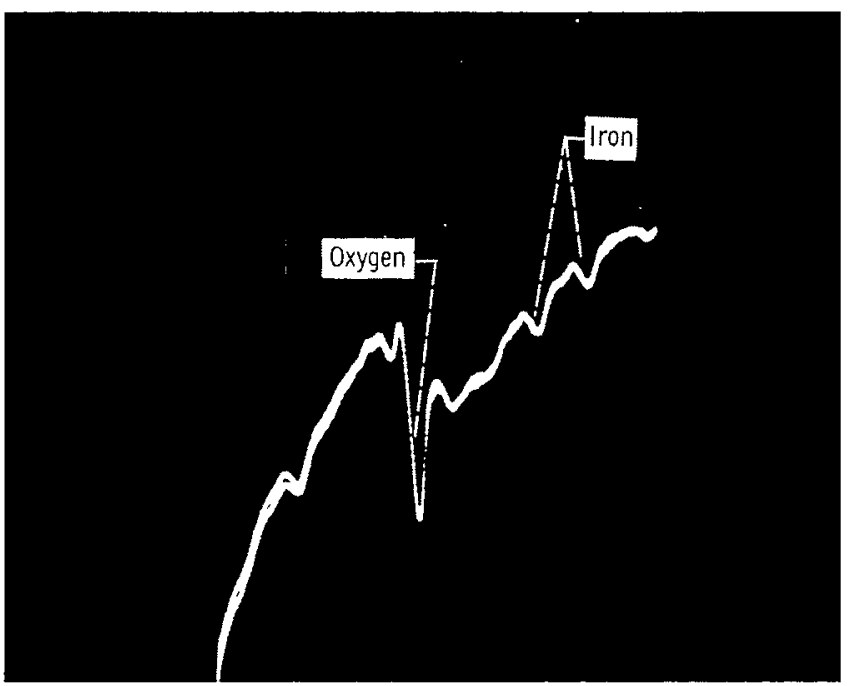

(a) Uxygen adsorbed 0.5 minute after sliding ceased.

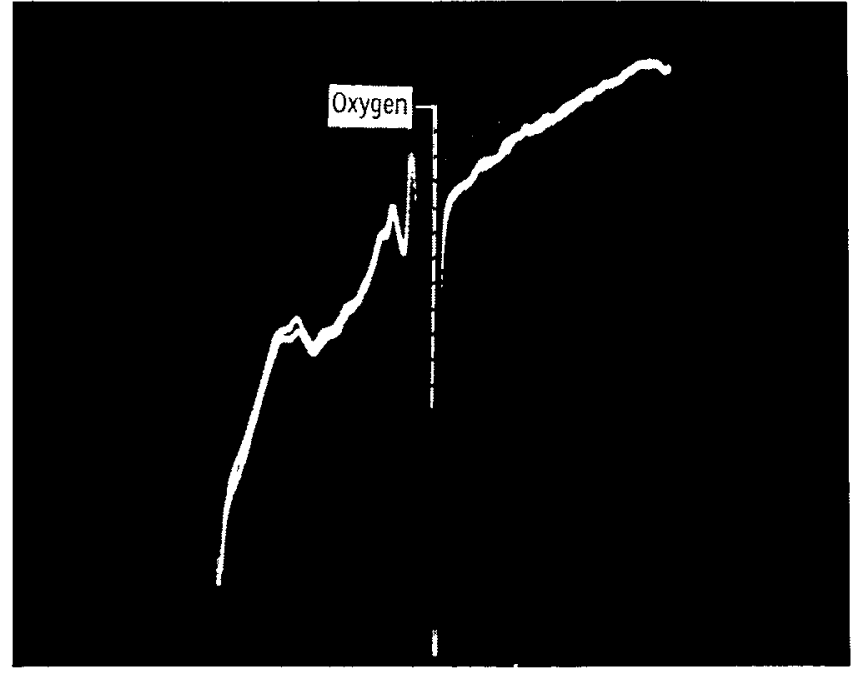

(b) Oxygen adsorbed 10 minutes after sliding ceased.

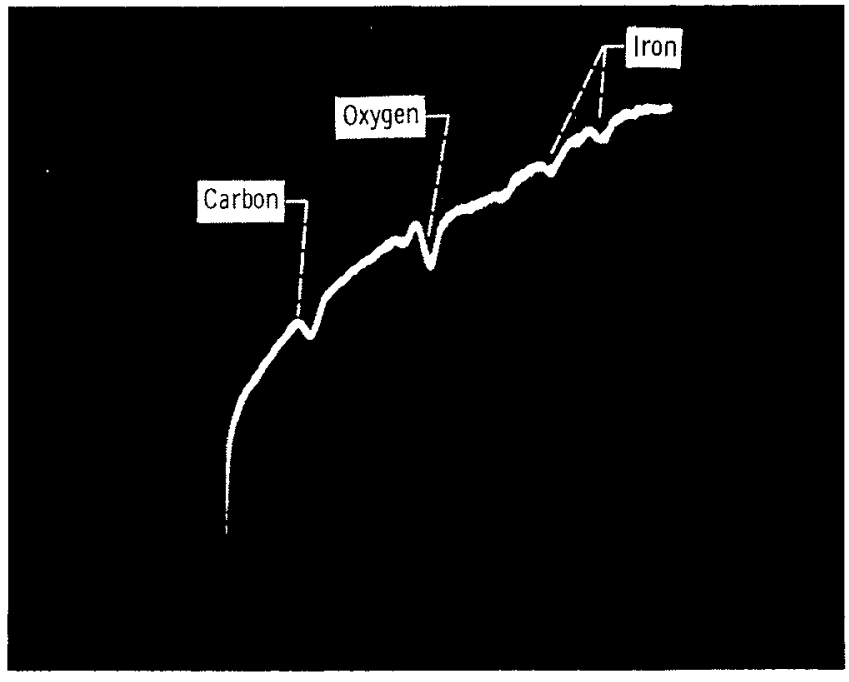

(c) Adsorption after sliding was resumed.

Figure 9. - Adsorption of residual gases containing oxygen to copper freshly transferred from copper rider to steel disk. Sliding velocity, 20 centimeters per minute; load, 500 grams; temperature, $23^{\mathrm{C}} \mathrm{C}$. 


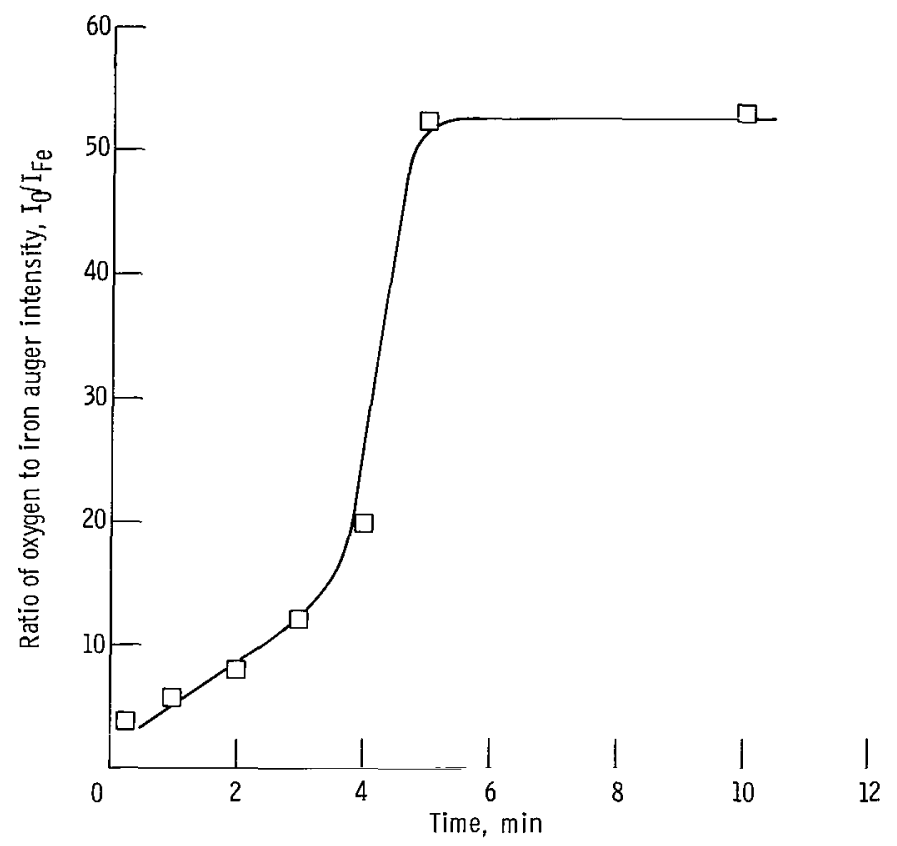

Figure 10. - Detection of oxygen associated with adsorption of residual gases (water and carbon monoxide) on freshly formed transfer film of copper to steel surface. Sliding velocity, 20 centimeters per minute; load, 500 grams; temperature, $23^{\circ} \mathrm{C}$; copper rider made 20 masses over disk surface. 


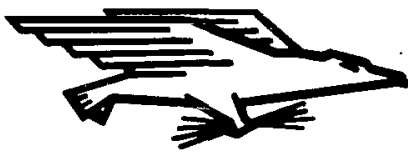

POSTAGE AND FEES PAID NATIONAL AERONAUTICS AND SPACE ADMINISTRATION

008001 C1 U 15710827 S00903DS

DEPT OF THE AIR FORCE

AF SYSTEMS COEHAND

$\therefore$

AF WEAPONS LAB (WLOL)

ATTN: $E$ LOD BOWMAN, CHIEF TECH LIBRARY

KIRTLAND AFB NM 87117

POSTMASTER :

If Undeliverable (Section 158

Postal Manual) Do Not Return

"The aeronautical and space activities of the United States shall be conducted so as to contribute . . to the expansion of buman knowledge of phenomena in the atmosphere and space. The Administration shall provide for the widest practicable and appropriate dissemination of information concerning its activities and the results thereof."

- National Aeronautics and Space ACt of 1958

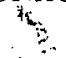

\section{NASA SCIENTIFIC AND TECHNICAL PUBLICATIONS}

TECHNICAL REPORTS: Scientific and technical information considered important, complete, and a lasting contribitrion to existing " knowledge.

TECHNICAL NOTES: Information less broad in scope but nevertheless of importance as a contribution to existing knowledge.

TECHNICAL MEMORANDUMS:

Information receiving limited distribution because of preliminary data, security classification, or other reasons.

CONTRACTOR REPORTS: Scientific and technical information generated under a NASA contract or granit and considered an important contribution to exksting knowledge.
TECHNICGA TRANSLATIONS: Information published in a foreign language considered to merit NASA distribution in English.

SPECIAL PÜBLICATIONS: Information derived from or of value to NASA activities. Publications include cónference proceedings, monographs, data compilations, handbooks, sourcebooks, and special bibliographies.

TECHNOLOGY UTILIZATION PUBLICATIONS: Information on technology used by NASA that may be of particular interest in commercial and other non-aerospace applications. Publications include Tech Briefs, Technology Utilization Reports and Technology Surveys.

Details on the availability of these publications may be obtained from:

SCIENTIFIC AND TECHNICAL INFORMATION OFFICE

NATIONAL AERONAUTICS AND SPACE ADMINISTRATION

Washington, D.C. 20546 